\title{
MOBILE ROBOT NAVIGATION PATH ALGORITHM IN 3D INDUSTRIAL INTERNET OF THING (IOT) ENVIRONMENT BASED ON 5G MOBILE COMMUNICATION
}

\author{
Belarusian National Technical University
}

\begin{abstract}
With the significant growth of the semiconductor industry, creating small devices with powerful processing ability and network capabilities are no longer a dream for engineers. Currently, Internet of Things (IoT) has become one of the hottest topics in both industry and academia of wireless communication field. The idea of the Internet of Things (IoT) is to connect every day physical objects such as microwave, doors, lightings and so on. The technical concept of the IoT is to enables these different physical objects to sense information using sensors and sends this information to a server. Industrial IoT is to integrate various technologies to improve business services in different sectors. It implicitly indicates the behavior of machine-to-machine communications. Each of industrial IoT as service domains has its own communication requirements that are measured differently in both such as reliability, Quality of service (QoS), and privacy. According to the development of industrial automation, the industrial Internet of things (IoT) is widely used in smart factories to capture the data and manage the production. One of the most important components of industrial IoT is the wireless sensor network (WSN), which are easy to deploy and use in indoor industrial environments for a lot of tasks, such as irrigation, machine condition monitoring, and environment monitoring. There are a lot of works focusing on the WSN in industrial IoT. For example, in, a WSN-based hidden Markov model is proposed to estimate the occupancy in the building (also see other works [1], [2]). In this paper, the research focus on 3-D mobile robot tracking in 5G wireless communication combine to sensor network and mobile robot path planning. The mobile robot can move fast in the three-dimensional (3-D) indoor industrial environment for many tasks such as the monitoring of possible damages on industrial plants [3], data gathering and transmission from wireless communication [4], transportation [5].
\end{abstract}

\section{Introduction}

The frequency bandwidth of information technology has already become too pricey, and with each passing day, they are becoming being extinct. Radio spectrum demand exponentially increasing after 2019, due to the rising desire from human being. The next generation wireless communication system considered as the one source of improved spectrum utilization, meet the needs of mobile robot in industrial Internet of Things (IoT) environment with explosive data growth [6]. Mobile robot in industrial IoT environment relies on the propagation of radio waves with large area coverage to transmit signals. A range of signals can be received by terminals in the same frequency band. Therefore, it is necessary to distinguish the information from different terminals especially in the applications of the industrial IoT which is a typical characteristic of data burst growth [7]. From the user view point the micro mobile robot characteristics of industrial IoT are displayed as a 3-D under actuated autonomous vehicle and wide- ly used to describe industrial robots as an example shown in Fig 1, [8].

Accordingly, several kinematic model that are important to the operation of the industrial robot system are identified. These kinematic model include: considering the time delay involved by communications and global path planning, the antenna array structure combine to the characteristic of millimeter wave from $5 \mathrm{G}$ wireless communication to obtain a better stability and the optimal system performance $[9,10]$. In the next sections a discussion will be related to the mobile robot is equipment with the sensor inertial measurement unit (IMU) with a communication technology. The mobile robot characteristics in industrial IoT environment depends mainly on the sensitivity received by the sensor and the wireless communication network time delay [11]. It is clear that the change in sensitivity has a strong effect on signal quality of the air channel and the capture image resolution of the access point to mobile robot in 


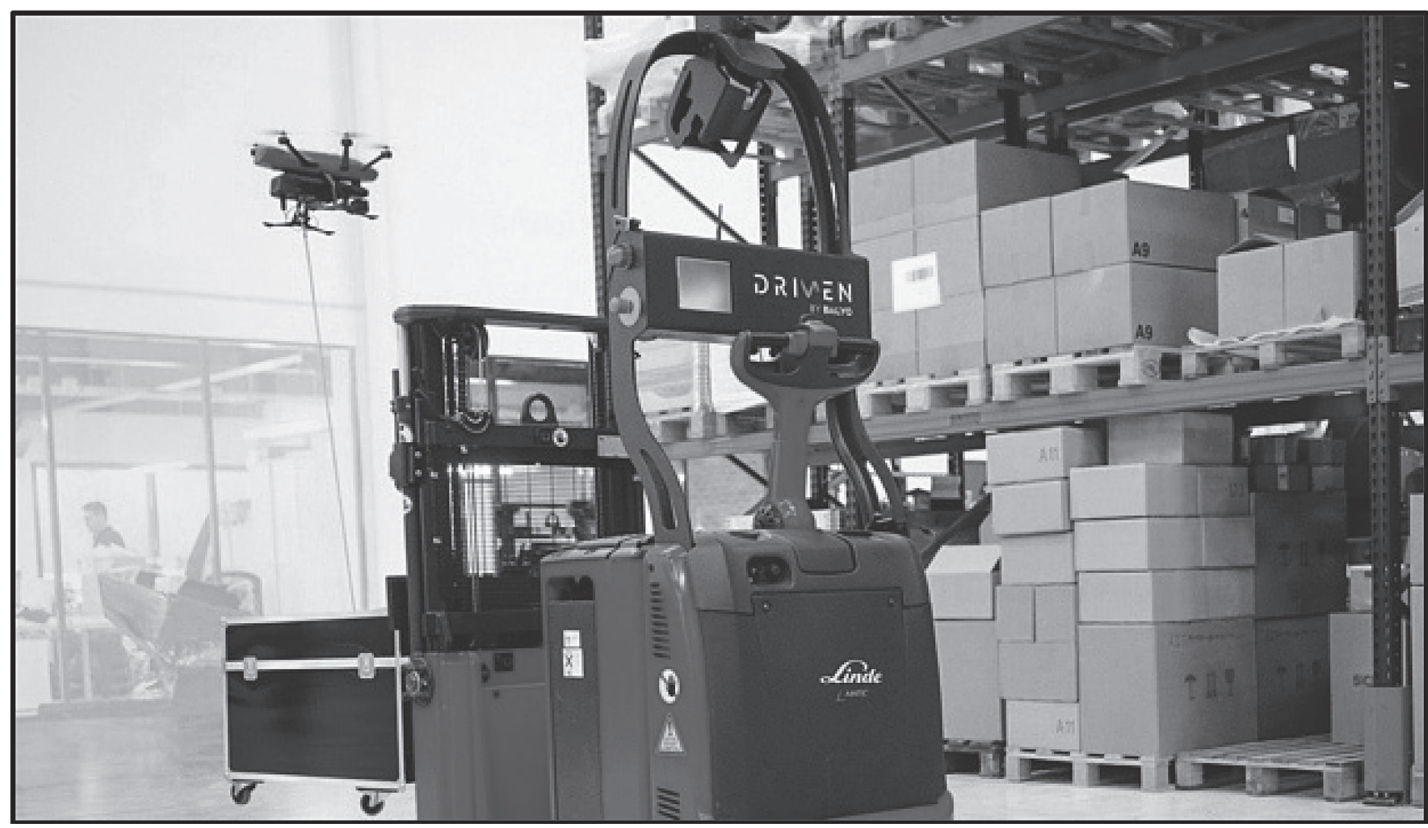

Figure 1. 3-D indoor industrial environment robot moving track

industrial 3-D environment, but negligible effect on the baseband signal processing.

The 3-D kinematic characteristics of a mobile robot is the extension of the 2-D kinematic planar analysis. There is a IMU and a wireless communication device have equipped in mobile robot in this paper. Moreover, there is a successful navigation path algorithm has been designed with real 3 -D robot [12]. The mobile robot in the 3-D industrial IoT space could be described as a Cartesian coordinate.

$$
s(t)=x(t), y(t), z(t) .
$$

Figure 2 shows the Cartesian coordinates in (1) of mobile robot in industrial 3D environment.

Several important parameters which are used to characterize mobile robot in industrial IoT communication environment are discussed in the following sections as mentioned earlier. The motion of mobile robot in 3-D industrial space in mathematical equations could be described as (2).

$$
\left\{\begin{array}{l}
\dot{s}=v_{r} \overrightarrow{\mathbf{i}}, \\
\dot{\overrightarrow{\mathbf{i}}}=\overrightarrow{\mathbf{u}} .
\end{array}\right.
$$

The $U_{M}$ is the maximum value of the norm of the input of two degrees of freedom control vector, usually written as $\|\overrightarrow{\mathbf{u}}\|<U_{M}$. The direction of robot's velocity is orthogonal to the input of two degrees of freedom control, it can be written as $\overrightarrow{\mathbf{i}} \perp \overrightarrow{\mathbf{u}}$. Moreover, according to IMU and the odometry data from wireless sensor feedback can ob- tain mobile robot's location $s(t)$ and the direction of robot's velocity $\overrightarrow{\mathbf{i}}(t)$. However, the control input $\overrightarrow{\mathbf{u}}$ has a constraint in minimum turning radius of the mobile robot is necessary to be explored in this dissertation. The minimum turning radius can be defined as follow (3):

$$
R_{\min }=\frac{v_{r}}{U_{M}}
$$

In this paper assumed a closed set $D$ with an arbitrary point in nation $\rho$, the safety distance range between $D$ and $\rho$ in minimum be written as (4)

$$
d_{s}(D, \rho):=\min \|\rho-D\|
$$

There is an initial torus, which is an extension of initial circle proposed in [13] for considering

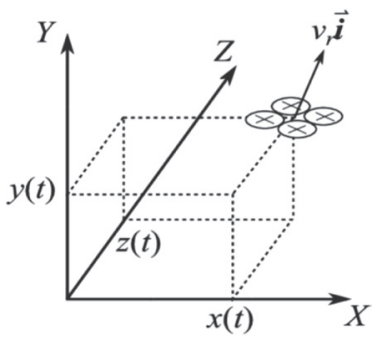

Figure 2. Mobile robot in 3D spatial coordinates where; $s_{i}=$ the number of ith mobile robot's position; $i=$ the current mobile robot's number; $v_{r}=$ the speed of robot movement, it is a constant speed in this dissertation; $R^{3}=$ Three-dimensional vector space; $\overrightarrow{\mathbf{i}}=$ the unit vector indicating the direction of robot's velocity, $\overrightarrow{\mathbf{i}} \in R^{3} ; \overrightarrow{\mathbf{u}}=$ input of two degree of freedom control, $\overrightarrow{\mathbf{u}} \in R^{3} ; \dot{s}=$ Find the first derivative of the displacement; $\overrightarrow{\mathbf{i}}=$ Find the first derivative of the unit vector of robot movement speed; $U_{M}=$ The maximum value of the norm of the input of two degrees of freedom control $\overrightarrow{\mathbf{u}}$ 


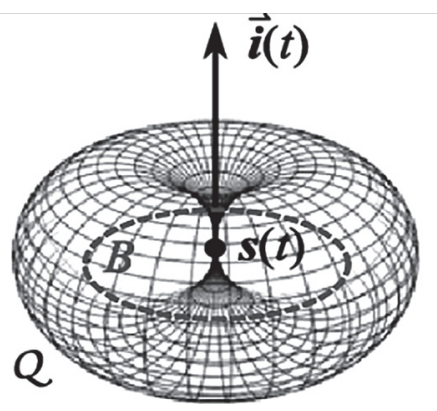

Figure 3. Composition of the minimum turning radius set $\mathrm{B}$

the minimum turning radius. When there is a set B satisfies the (2.5) and (2.6) equations.

$$
\begin{gathered}
B=\left\{\rho \in R^{3},(\rho-s) \perp \overrightarrow{\boldsymbol{i}},\|\rho-s\|=R_{\min }\right\} \\
Q:=\left\{\rho \in R^{3}, d_{s}(B, \rho):=R_{\min }\right\}
\end{gathered}
$$

The minimum turning radius can be found is shown on the circular dotted line below in Fig 3.

In an industrial IoT environment applications exists two different obstacle scenarios in different irregular shapes and dynamic velocities can be divided into static state and moving state (walls, other mobile robot, etc.) To ensure the reliability and timeliness of obstacle detection, we consider to deploy $5 \mathrm{G}$ massive MIMO antenna in millimeter wave communication for increase spatial information throughput while ensuring the directionality of information transmission combined with sensor network in the workspace. In Fig 4, each sensor acquisition terminal uses a 3-D range finder to measure the obstacle distance in different directions in ideal circumstances. There are two types of 3-D range finder in industrial applications commonly be used. The first type provides omnidirectional measurements of distance named spinning 2-D range finder [14], The second type only measures the distance based 3D capture hardware system design method in a limited field of view named time of flight (ToF) camera [15]. Assumption 2.1: The obstacle scenarios is static and obstacle's location is known.

The sensor nodes usually are fixed on the top of wall, ceilings. The received signal strength indicator (RSSI) is used for current WSN and flying robots estimating. Therefore, the locations of both the sensor nodes and the flying robots can be estimated based on RSSI [16]. Wireless sensor nodes in industrial IoT environment combine to

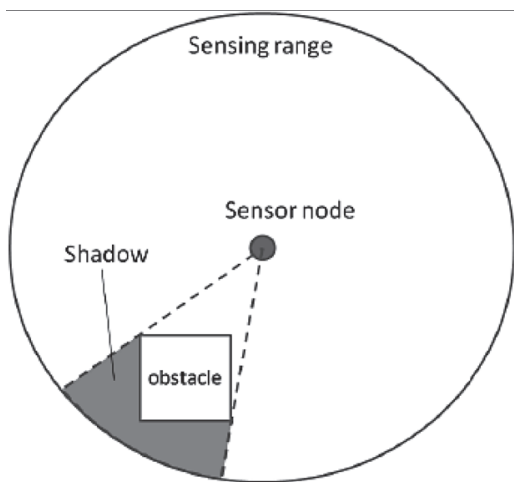

Figure 4. The range finder in industrial wireless sensor network environment

magnetic sensor and gravity sensor to obtain the attitude of each sensor node. Moreover, the mobile robots navigate algorithm is controlled by a central computer. The central computer could collect the real-time measurements of the obstacles rapidly from each 3-D range finder according to connects to one of the sensor nodes in industrial IoT 5G WSN communication environment. Then, the 3D-detection area topographic map of the unoccupied area will be build by central computer from measurements data value. Furthermore, the mobile robot in the industrial IoT workspace can communicate to the WSN. The mobile robot is controlled by the central computer via WSN. In practical implementations in industrial IoT environments is shown in Fig 5, the mobile robot uploads the sensor data to the central computer.

The structure of 5G WSN in Fig 5 consists of:

1) A central computer, representing central master control module, central processing module completes data processing and fusion for the data collection, analysis, and early warning from the industrial IoT environment,

2) A flying robot representing the electronic equipment operates reliably in industrial IoT environment,

3) A image sensor, is an optoelectronic device in photoelectric conversion function for convert-

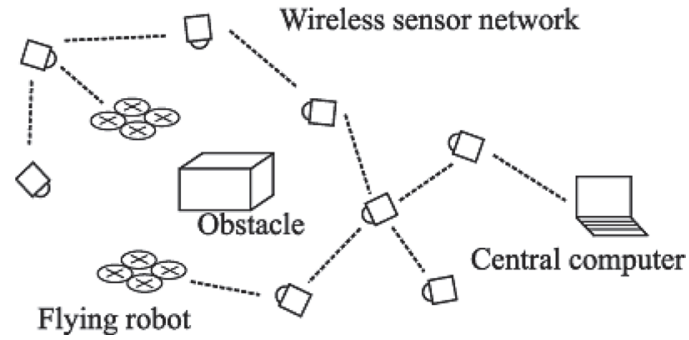

Figure 5. Structure of 5G WSN implementations in industrial IoT environments 


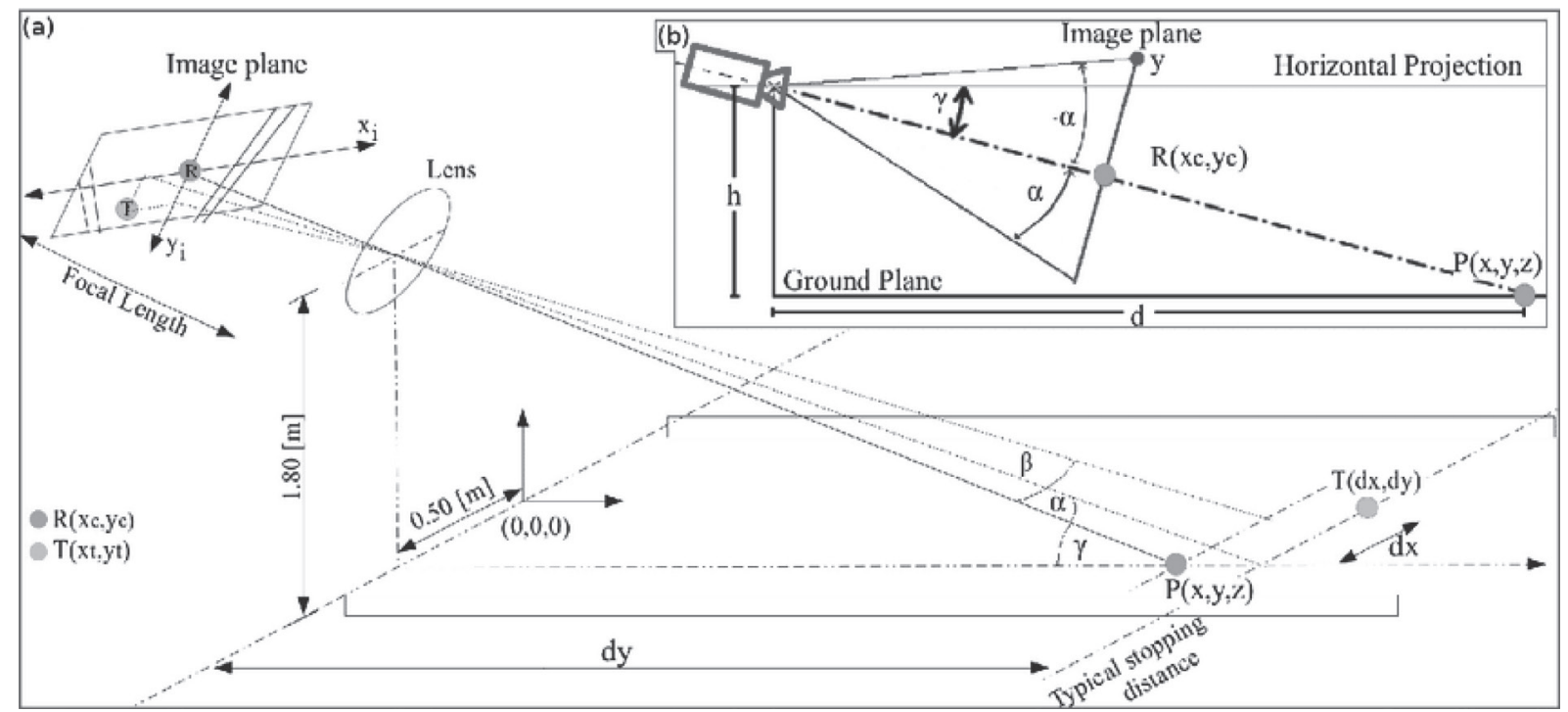

Figure 6. Wireless sensor node detects objects region

ing the light image on the photosensitive surface into an electrical signal.

4) A large number of image sensors form a wireless sensor network in a multi-hop or a mesh manner to collaborative obstacle perception, collect, process, and transmit the information from the perceived objects in the geographic area to central computer.

In the industrial environment, the sensor nodes detect the obstacles and mobile robot position. For any sensor node detects objects region can be written as $\mathbf{N}_{i}^{t}$, $\mathrm{i}$ is the image sensor's or mobile robot's number, $t$ is the image sensor's perceived time. the image sensor's measurements could be converted from its local coordinate system with its location to the global coordinate system for a region $\mathbf{N}_{i}^{t}$. Fig 6, (below) shows a detected region of the image sensor node in coordinate system.

The first definition gives the detected region $\mathbf{N}_{i}^{t}$ is a closed and continuous point set in the three-dimensional vector space $R^{3}$ for any mobile robot's number $i$ and image sensor's perceived time $t$. Let $d_{s}$ is a constant in the second definition, the boundary of a closed set $D$ can be expressed as $\partial D$. a set $R\left[D, d_{s}\right]$ stand for the $d$-reduction of the closed set $D$ defined as follow (7):

$$
R\left[D, d_{s}\right]:=\left\{\rho \in D: d(\partial D, \rho) \geq d_{s}\right\}
$$

Let a safety range $d_{s}$ is a constant in the third definition, the set $\varepsilon\left[D, d_{s}\right]$ is the $d$-enlargement of the closed set $D$ defined as follow (8) and shows in Fig. 7.

$$
\varepsilon\left[D, d_{s}\right]:=\left\{\rho \in R^{3}: d(D, \rho) \leq d_{s}\right\}
$$

Assumption 2.2: a sphere could be written as the set e $\left[s_{i}(t), R_{r}\right]$ with a given radius $R_{r}$ covers mobile robot in the working space.

In industrial IoT environment each mobile robot's location should be uploaded to the central computer by the 3-D range image finder sensors detection. Therefore, the error correction for mobile robot's navigation is applied [17]. Moreover, for any mobile robots on each 3-D region such as $\mathbf{N}_{i}^{t}, i=1,2,3, \ldots$, should be involved to interference cancellation by radio wave filter. The robots' positions and radius $R_{r}$ are used for recognizing the occupied positions belonging to any robots and the sensor node number $i$, then occupied positions depth measurements corresponding can be achieved by using a low-pass filter. The estimated region of $\mathbf{N}_{i}^{t}$ by using radio wave filter could be denoted as $\mathrm{N}_{i}^{t}$. There has an unoccupied area from image sensor detection $A(t)$ can be calculated as follow (9):

$$
A(t)=\bigcup_{i=1}^{m} \widehat{N_{i}^{t}}
$$

where $m=$ the number of the sensor nodes.

Assumption 2.3: there is an arbitrary point $p$ in the set $A(t)$, and the boundary of $A(t)$ denoted as $\partial A(t)$. the minimum distance $d(\partial A(t), p)$ with respect to time $t$ is $\leq v_{r}$, where $v_{r}$ is the speed of

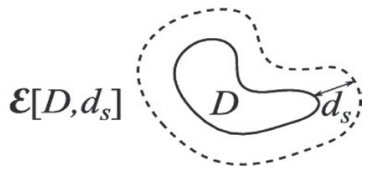

Figure 7. The boundary of a closed set D and its safety range $d_{s}$ 
robot movement, it is a constant speed and a safety range $d_{s}>0$ has defined in a constant. at any time $t$, the mobile robot should keep from the boundary $\partial A(t)$.

Assumption 2.4: The set $R\left[A(t), d_{s}\right]$ is a connected set in any time $t$, at the same time, the robot's initial position $s_{0}$ belongs to the set $R[A(0)$, $\left.d_{s}\right]$ and is far away from the boundary of $A(0)$.

The mobile robot could travel in the dynamic and deformable environment in $d_{s}$-reduced region to avoid any other mobile robot to reach a target in a short trajectory. In this paper, the target belongs to the set $R\left[A(t), d_{s}\right]$ and far away from the robot's initial position $s_{0}(t)$, at any time $t$.

\section{Characteristics of mobile robot navigation algorithm in industrial IoT}

The performance characteristics of a mobile robot tracking depend on its basic relatively short instant safe path denoted by $P^{*}$, central computer computing power and navigation algorithm. The paths $P^{*}$, are described by their characteristic of successive and finite equally spaced points. it can be written as $P^{*}(0), P^{*}(1), \ldots, P^{*}(n)$, where $n=$ the length of this discrete path; $P^{*}(0)=$ the current position $s(t)$ of mobile robot.

The mobile robot in a future time $t+k \delta$ for any random position $\mathrm{k}$ could be represented as $P^{*}(k), \delta$ is an impact variable of time. A constant $L$ equal to $v_{r} \delta$ is the distance between any two successive points. The radius of the circumscribed circle of any three successive points should be $\geq R_{\min }$, and the initial torus $Q$ should be consist by $P^{*}(0)$. In this chapter, there are two conditions of a mobile robot in industrial IoT environment be considered. In the first condition, the mobile robot is steady and only has one point $P^{*}(n=0)$ at its current position after it reaches a target. In the second condition, the mobile robot according to the optimal path $P^{*}(n>0)$ travelling to an arranged target. Let $\delta$ be the sampling interval in the distance between any two successive points. the unoccupied area $A(t)$ is calculated by the central computer to obtains real-time positions $s_{1}(t), s_{2}(t), \ldots$ according to the WSN to update the paths $P^{*}(1)$, $P^{*}(2), \ldots$ for the mobile robot. Let $T$ be a positive integer stand for time window and its properties of generated path $P^{*}$ is from the robot's current position $s(t)$ to the target $T . P^{*}$ is guaranteed to be collision-free to the obstacles in time $[t, t+T \delta]$. The mobile robot finally can arrive to the target successful without any collisions according to the update $P^{*}$ at an impact variable of time. Here gives a definition and assumption in dynamic industrial IoT environment for potentially unsafe regions. The obsoletely safe region at time $t+k \delta, k \leq T$ could be written as (10)

$$
\bar{A}(t, k):=R\left[A(t), k \delta v_{\max }\right]
$$

among them, $T$ is over time window, $k$ is a constant $k=0,1,2, \ldots$ and the extension as (11) from (10) is an instant safe path in the time window $T$ :

$$
\bar{A}(t, k):=R\left[A(t), T \delta v_{\max }\right], k>T
$$

the mobile robot should be considered to avoid collision with other robot in industrial IoT environment. Moreover, a valid area $\hat{A}(t, k)$ in any future time $t+k \delta$ is defined in (12). The symbol $\backslash$ denotes the set difference.

$$
\hat{A}(t, k):=\bar{A}(t, k) / \bigcup_{j \neq i} \varepsilon\left[p_{j}^{*}(k), R_{r}\right]
$$

Thus, the (13) shows the mobile robot's path $P^{*}$ in combine to the above formula.

$$
p_{j}^{*}(k)=p_{j}^{*}(n)
$$

The path $P^{*}$ is called a target-reaching path if $\left\|T-P^{*}(n)\right\| \leq L$, for any $t$ and $k$, the set $R[\hat{A}(t, k)$, $\left.d_{S}\right]$, ] is a connected set and the destination point $T$ belongs to the set $R\left[\hat{A}(t, k), d_{s}\right]$.

There are two different parts of the proposed navigation algorithm will be introduced in next coming chapters. The first part of the algorithm is rough path generation and the path planning following in the second part. A rough path $P$ is generated by the probabilistic roadmap algorithm when the mobile robot needs to be navigated to the arranged destination in any time step. Then, the instant path $P^{*}$ calculated by path planning algorithm is adjusted from rough path $P$. the mobile robot can avoid collision from any obstacles and other robot to arrived the destination successfully in the industrial IoT workspace environment according to above algorithm combine to the WSN in $5 \mathrm{G}$ communication.

\section{Impact of rough path generation parameters for a mobile robot with an arranged destination}

The shortest rough path $P$ during the area $R[A(t)$, $\left.d_{s}+T \delta v_{\max }\right]$ is created by probabilistic roadmap method to provide the routing scheme for mobile robot with an arranged destination point $T$ in in- 


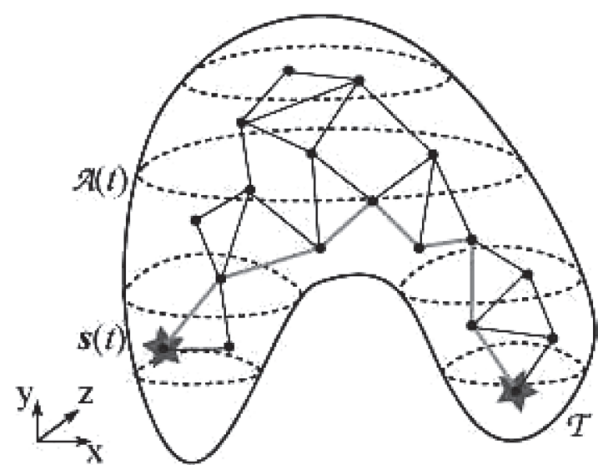

Figure 8. The mobile robot in probabilistic roadmap method to arrive destination point

dustrial IoT environment [18]. The rough path generation algorithm as in Fig 8.

Figure 8 (below) gives a definition and algorithm description. $D$ is a closed point set, a line segment path between any two points is stand for a valid routing path, however the line segment between two points should not intersect with the boundary of $D$.

There has randomly distributed points from the set $R\left[A(t), d_{s}+T \delta v_{\max }\right]$ represents the mobile robot's current position $s(t)$ and destination points $T$ for motion tracking in this dissertation. The shortest valid path from $s(t)$ to $T$ consisting of a few random points number can be calculated according to Dijkstra's algorithm which may represent, for example, computer routing protocol algorithm and wireless transmission path calculation. For a given source node $s(t)$, the Dijkstra algorithm finds the shortest path between that node and every other.

\section{The mobile robot path planning in industrial IoT environment}

For simplicity in analyzing characteristics of mobile robot path planning algorithm, the instant safe path $P^{*}$ are realized in the valid area $R[\hat{A}(t, k)$, $\left.d_{s}\right]$ and are hence modelled using mathematic simulation. It helps in predicting behavior under various environmental conditions, and further in help analysis rough path characteristic curves.

The common approach is to utilize the Mathematical calculation, which is primarily based on vectors superposition of linear space. There is a model have been proposed for the simulation of a path planning algorithm various vectors intensities and calculation conditions.

The key factor that affects the results of the simulation and accuracy in representing the nonlinear characteristics of the mobile robot path plan- ning is mathematic modeling [19]. There are different kinds of parametric models presented in various literatures in the past few decades, like wireless communication in internet of vehicle navigation model, automatic driving navigation model, automatically avoid obstacles and much more.

The most commonly used model is wireless communication navigation model, as they provide better relations with a practical internet data center keeping in mind the simplicity in implantation and the iteration speed in the extracting parameters gives minimum error with respect to characteristics of path planning or navigation analysis as per manufacturer's datasheet.

Before we elaborate on the discussion of the mathematical model for mobile robot path planning we will introduce the following acronyms that will assist in better understanding the following generated equations which are related to the further models. The different parameters are listed below in table 1 where a set of symbols are introduced with a brief explanation of each acronym.

Ta b le 1. Parameters of the mobile robot path
planning method
\begin{tabular}{|c|l|}
\hline$F_{I}$ & $\begin{array}{l}\text { Equidistant sampling point } \\
\text { separation distance }\end{array}$ \\
\hline$F_{\mathrm{R}}$ & $\begin{array}{l}\text { Minimum distance from current } \\
\text { position to boundary point }\end{array}$ \\
\hline$F_{P}$ & $\begin{array}{l}\text { A vector pointing to destinetion, } \\
\text { only related to one previous point }\end{array}$ \\
\hline$F_{C}$ & $\begin{array}{l}\text { A vector field, which guarantees } \\
\text { that the path satisfies the non- } \\
\text { integrity constraint }\end{array}$ \\
\hline
\end{tabular}

There is a well-known and widely used models, the level of complexity, depending on the purpose it used for: The version of this model is presented in the following. The path points of the rough path $P$ denoted as $P_{(0)}, P_{(1)}, \ldots, P_{(n)}$ and vector fields $F_{I}, F_{R}, F_{P}, F_{C}$, in $R^{3}$ to help adjust the path points of $P$. The resultant in the rough path vector of these four fields at point $P_{K}$ is shown in (14)

$$
\vec{F}\left(P_{K}\right)=\overrightarrow{F_{I}}\left(P_{K}\right)+\overrightarrow{F_{R}}\left(P_{K}\right)+\overrightarrow{F_{P}}\left(P_{K}\right)+\overrightarrow{F_{C}}\left(P_{K}\right)
$$

The $F_{I}$ could guarantees the interval between any two successive points of $P$ is approximately equal to the distance between destination $T$ and finite spaced point $L$. For any $k \neq 0$, let $\overrightarrow{\vec{l}_{k}}$ be the vector from $P_{k}$ to $P_{k-1}$ as in Fig 9. $\overrightarrow{F_{I}}\left(P_{K}\right)$ in mathematical expressions as (15) 


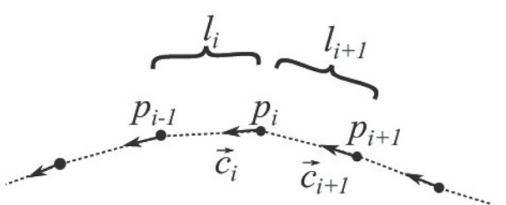

Figure 9. The vector from finite spaced point

$\overrightarrow{F_{I}}\left(P_{K}\right):= \begin{cases}G_{I}\left(b(k) \overrightarrow{l_{k}}-b(k+1) \overrightarrow{l_{k+1}}\right) & \text { if } k \neq n \\ G_{I}\left(b(k) \overrightarrow{l_{k}}\right) & \text { if } k=n\end{cases}$

Where $G$ is a tunable gain and $b(k)$ is a fixed arithmetic expression in (16). This model without the consideration for the losses due to the module's internal series resistance, as well as contacts and interconnections between cells and modules in this dissertation. It has a relatively good approximation precision and it is perhaps the most suitable model for the Mobile robot navigation communication in industrial IoT environment, as it offers good compromise between approximation precision and simplicity [20].

$$
b(k):=1-\frac{L}{\left\|\overrightarrow{l_{k}}\right\|}
$$

Let $\overrightarrow{\gamma_{k}}$ is the shortest vector from current point $P_{K}$ to the boundary of valid area when the $\hat{A}(t, k) \geq d_{s}$ in Fig 10. In this moment, $\overrightarrow{F_{R}}\left(P_{K}\right)$ could be written as (17).

$$
\overrightarrow{F_{R}}\left(P_{K}\right):= \begin{cases}G_{R}\left(1-\frac{d_{s}}{\left\|\overrightarrow{\gamma_{k}}\right\|}\right) \overrightarrow{\gamma_{k}} & \text { if }\left\|\overrightarrow{\gamma_{k}}\right\| \leq d_{s} \\ \overrightarrow{0} & \text { if } \overrightarrow{\gamma_{k}}>d_{s}\end{cases}
$$

From the current point $P_{n}$, there has a unit vector pointing $g$ pointing to the destination points $T$, and let $\overrightarrow{\boldsymbol{h}_{\boldsymbol{k}}}$ be the vector from the point $P_{n}$ to the

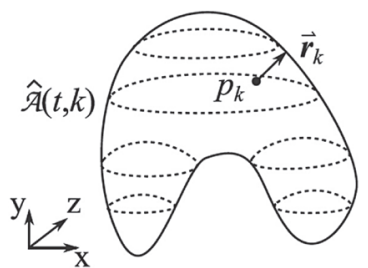

Figure 10. Current point $P_{K}$ to the boundary of valid area

closest point at the circle $B$. The $\overrightarrow{F_{P}}$ and $\overrightarrow{F_{c}}$ can be calculated as (18) and (19).

$$
\begin{gathered}
\overrightarrow{F_{P}}\left(P_{n}\right):=G_{P} \overrightarrow{\mathcal{g}} \\
\overrightarrow{F_{C}}\left(P_{K}\right):= \begin{cases}G_{c}\left(1-\frac{R_{\min }}{\left\|\overrightarrow{h_{k}}\right\|}\right) \overrightarrow{h_{k}} & \text { if }\left\|\overrightarrow{h_{k}}\right\| \leq R_{\min } \\
\overrightarrow{0} & \text { if } \overrightarrow{h_{k}}>R_{\text {min }}\end{cases}
\end{gathered}
$$

There has a smallest error between $P_{K}$ and equilibrium point when the appropriate attenuation be chosen such that each $P_{K}$ can converge fast to the position where $\left\|\vec{F}\left(P_{K}\right)\right\|<F_{t h}$ in the proposed path planning algorithm. The instant safe path $P^{*}$ in current time step could be achieved with the proposed algorithm.

\section{Conclusion}

In this paper, we proposed a WSN based on $5 \mathrm{G}$ wireless advantage collision-free navigation method for mobile robot in the industrial IoT environment. A mobile robot cannot be equipped with heavy obstacle detection sensors. Therefore, to solve the navigation problem, a WSN consisting of 3-D range finder is involved to detect the static and dynamic obstacles in the workspace. With the navigation of the sensor network, only a path tracking controller is required for each mobile robot. The robot can be navigated directly in the industrial workspace without any specialization.

\section{REFERENCE}

1. Li, S. Compressed sensing signal and data acquisition in wireless sensor networks and Internet of things. / S. Li, L. D. Xu, X. Wang, - IEEE Trans. Ind. Informat., - 2013. Vol. 9. No. 4, p. 2177-2186.

2. Yan, H. Superframe planning and access latency of slotted MAC for industrial WSN in IoT environment. / H. Yan, Y. Zhang, Z. Pang, L.D.Xu, - IEEE Trans. Ind. Informat., 2014. Vol. 10. No. 2, p. 1242-1251.

3. Moranduzzo T. Monitoring structural damages in big industrial plants with UAV images. / T. Moranduzzo and F. Melgani, in Proc. - 2014 IEEE Geosci. Remote Sens. Symp., - Quebec City, Canada, -2014, p. 4950-4953.

4. Dong, M. UAV-assisted data gathering in wireless sensor networks. / M. Dong, K. Ota, M. Lin, Z. Tang, S. Du, H. Zhu, J. Supercomput., - 2014. Vol. 70. No. 3, p. 1142-1155.

5. Harik, E. H. C. UAV-UGV cooperation for objects transportation in an industrial area. / E. H. C. Harik, F. Gu'erin, F. Guinand, J. F. Breth'e, and H. Pelvillain, Proc. - 2015 IEEE Int. Conf. Ind. Technol - Seville, Spain, - 2015. p. 547-552.

6. Kreibich, O. Quality-based multiple-sensor fusion in an industrial wireless sensor network for MCM,” / O. Kreibich, J. Neuzil, and R. Smid - IEEE Trans. Ind. Electron., - 2014. Vol. 61, no. 9, p. 4903-4911. 
7. Iqbal, Z. A cooperative wireless sensor network for indoor industrial monitoring. / Z. Iqbal, K. Kim, and H. N. Lee, IEEE Trans. Ind. Informat., - 2017. Vol. 13, no. 2, p. 482-491.

8. Matveev, A. S. A method of reactive 3D navigation for a tight surface scan by a nonholonomic mobile robot. / A. S. Matveev, K. S. Ovchinnikov, and A.V. Savkin, - Automatica, - 2017. Vol. 75, p. 119-126.

9. Ping, P. Flexible Multiple Access Control Algorithm in 5g Mobile Wireless System. / P. Ping, Y.N. Petrenko, Информатика Journal, - 2018. Vol. 15, No. 3 p. 93-101.

10. Ping P. The physical layer technologies in $5 \mathrm{~g}$ mobile communication system. / P. Ping, Y.N. Petrenko, - International Conference on Physics, Computing and Mathematical Modeling (PCMM). - Shanghai, China, - 2018. p. 111-117.

11. Ai, B. Occupancy estimation for smart buildings by an auto-regressive hidden Markov model. / B. Ai, Z. Fan, and R. X. Gao, in Proc. - 2014 Amer. Control Conf., - Portland, OR, USA, - 2014, p. 2234-2239.

12. Wang, C. A strategy for safe 3D navigation of non-holonomic robots among moving obstacles. / C. Wang, A. V. Savkin, and M. Garratt, - Robotica, - 2018. Vol. 36, No. 2, p. 275-297.

13. Hang, L. Wireless Sensor Network Based Navigation of Micro Flying Robots in the Industrial Internet of Things. / L. Hang, and A. V. Savkin. - IEEE Transactions on industrial informatics, - 2018. Vol. 14. No. 8, p. 3524-3533.

14. Olivka, $\mathbf{P}$. The design of 3D laser range finder for robot navigation and mapping in industrial environment with point clouds preprocessing. / P. Olivka, M. Mihola, P. Nov'ak, T. Kot, and J. Babjak. - in Modelling and Simulation for Autonomous Systems. - Rome, Italy: Springer-Verlag, - 2016, p. 371-383.

15. Aleny`a, G. Using ToF and RGBD cameras for 3D robot perception and manipulation in human environments. / G. Aleny`a, S. Foix, and C. Torras. - Intell. Service Robot. - 2014, Vol. 7, No. 4, p. 211-220.

16. Shih, C. Y. COLA: Complexity-reduced trilateration approach for 3D localization in wireless sensor networks. / C. Y. Shih and P. J. - 4th Int. Conf. Sensor Technol. Appl. Mestre, Italy, - 2010, p. 24-32.

17. Held, D. Robust real-time tracking combining 3D shape, color, and motion. / D. Held, J. Levinson, S. Thrun, and S. Savarese. - Int. J. Robot. Res. - 2016. Vol. 35, No. 1-3, p. 30-49.

18. Rosmann, C. Integrated online trajectory planning and optimization in distinctive topologies. / C. Rosmann, F. Hoffmann, and T. Bertram. - Robot. Auton. Syst. - 2017. Vol. 88, p. 142-153.

19. Indiveri, G. A proof of concept for the guidance of 3D underactuated vehicles subject to constant unknown disturbances. / G. Indiveri, S. Cret'1, and A. A. Zizzari. - IFAC Proc. - 2012. Vol. 45, No. 27, p. 307-312.

20. Wang, F. An efficient UAV navigation solution for confined but partially known indoor environments. / F. Wang, K. Wang, S. Lai, S. K. Phang, B. M. Chen, and T. H. Lee. - in Proc. 11th IEEE Int. Conf. Control Autom. - Taichung, Taiwan. 2014, p. 1351-1356.
Поступила
После доработки
22.02.2019
Принята к печати
22.11.2018
22.02 .2019
25.03.2019

PEI PING, ПЕTРЕНКО Ю.Н.

\section{ААГОРИТМ 3D НАВИГАЦИИ МОБИАЬНОГО РОБОТА В СРЕАЕ ПРОМЫШАЕННОГО ИНТЕРНЕТА ВЕЩЕЙ НА ОСНОВЕ 5D МОБИАЬНОЙ КОММУНИКАЦИИ}

\footnotetext{
При значительным развитии полупроводниковой техники, создающей миниатюрные устройства с мощной способностью в обработке данных и обладающими сетевыми возможностями, в настоящее время Интернет вещей (Internet of Things) (IoT) стал одной из самых горячих тем в промышленности и в коммуникачии. Идея IоT состоит в том, чтобы постоянно соединять физические объекты, такие как микроволновая печь, двери, отопительные прибоpы, освещение, холодильники и так далее-все, что среди нас. Техническое понятие ІоТ позволяет этим различным физическим объектам быть представленными информачией о себе за счет сигналов датчиков и хранить эту информацию на сервере. Промышленный Industrial IІоТ должен объединить различные технологии, чтобы улучшить коммуникации от машины к машине. У каждого из промышленных элементов ІоТ есть свои собственные коммуникационные требования, которые характеризуют надежность и качество обслуживания (QoS). Согласно развитию промышиленной автоматизации, промышленный Интернет вещей ІІоТ широко используется на "умных" предприятиях, чтобы собрать данные, обработать их и оптимально управлять производством. Один из самых важных компонентов ІІоТ-беспроводная сеть датчиков, которую легко развернуть в уже имеющихся производственных условиях для решения большого количества задач, таких как контроль хода производственного процесса и контроль окружающей среды.

B статье сосредоточено внимание на $3 D$-навигации мобильного робота в $5 G$-коммуникачии совместно с сетью датчиков для планирования пути робота. Мобильный робот может быстро перемещаться в трехмерной (3D) внутренней промышленной среде для решения многих задач, таких как мониторинг возможных поломок оборудования на предприятии [3], сбор данных и их передача по каналам беспроводной связи [4], решение транспортных задач [5].
}

Ключевые слова: Internet вещей (ІоТ), беспроводная сеть датчиков, коммуникации, промыщленная навигация. 

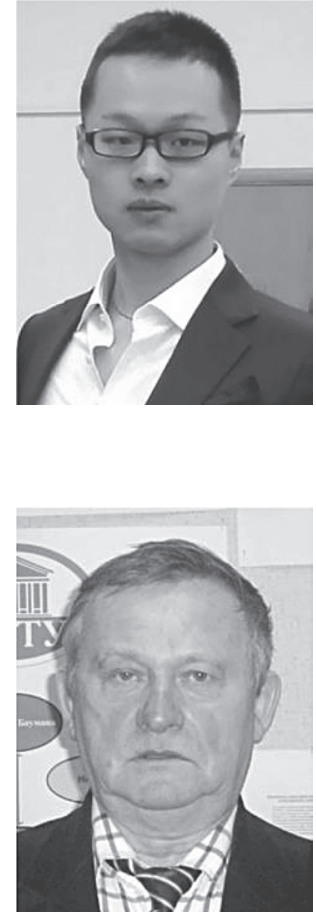

Pei Ping was born in Xi'an, China. He received the bachelor's degree in information technology engineering from Rovaniemi University of Applied Sciences, Finland, in 2013. The M.Sc. degree in system analysis and data processing from Belarusian National Technical University 2017. he is currently working toward the Ph.D. Degree at the department of information systems and technologies in Belarusian National Technical University (BNTU), Minsk, Belarus, His interest includes Flexible control of automatic traffic machine collision avoidance based on wireless mobile communication system, multiplexing algorithm in mobile wireless communication system. He also is a professional network engineer from HUAWEI company.

Yury N. Petrenko, IEEE Life member. He has been teaching Automatic Control of Electric Drives, Numerical Control Systems and Programmable Logic Controllers. He is an author, Editor and Co-Author of 7 books, recommended by Ministry of Education for University and College -level engineering education and 2 Monographs (in coop). His main research interests in recent years include data signal processing, new control techniques applied to power electronics and electric drives, control and automation of the photovoltaic power station, predictive control systems synthesis and analysis. 